\section{(6) OPEN ACCESS}

\title{
MRI assessment of early response to certolizumab pegol in rheumatoid arthritis: a randomised, double-blind, placebo-controlled phase IIIb study applying MRI at weeks 0, 1, 2, 4, 8 and 16
}

\author{
M Østergaard, ${ }^{1}$ L T H Jacobsson, ${ }^{2}$ C Schaufelberger, ${ }^{2,}{ }^{\dagger}$ M Sejer Hansen, ${ }^{3}$ \\ J W J Bijlsma, ${ }_{1}^{4}$ A Dudek, ${ }^{5}$ M Rell-Bakalarska, ${ }^{6}$ F Staelens, $^{7}$ R Haake, \\ B Sundman-Engberg, ${ }^{9} \mathrm{H}$ Bliddal ${ }^{10}$
}

\section{Handling editor Tore K Kvien \\ For numbered affiliations see end of article. \\ Correspondence to \\ Professor Mikkel Østergaard, Copenhagen Center for \\ Arthritis Research, Center for Rheumatology and Spine \\ Diseases, Glostrup Hospital, Nordre Ringvej 57, Glostrup DK-2600, Denmark; \\ mo@dadlnet.dk}

†Deceased July 2014

Received 25 July 2014 Revised 12 November 2014

Accepted 15 November 2014 Published Online First

15 December 2014

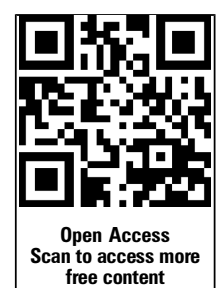

CrossMark

\begin{tabular}{l}
\hline To cite: Østergaard M, \\
Jacobsson LTH, \\
Schaufelberger C, et al. Ann \\
Rheum Dis 2015;74: \\
1156-1163. \\
\hline
\end{tabular}

\section{ABSTRACT}

Objectives To identify the first time point of an MRIverified response to certolizumab pegol (CZP) therapy in patients with rheumatoid arthritis (RA).

Methods Forty-one patients with active RA despite disease-modifying antirheumatic drug therapy were randomised 2:1 to CZP (CZP loading dose $400 \mathrm{mg}$ every 2 weeks at weeks 0-4; CZP 200 mg every 2 weeks at weeks $6-16$ ) or placebo $\rightarrow$ CZP (placebo at weeks $0-2$; CZP loading dose at weeks 2-6; CZP $200 \mathrm{mg}$ every 2 weeks at weeks 8-16). Contrast-enhanced MRI of one hand and wrist was acquired at baseline (week 0 ) and weeks 1, 2, 4, 8 and 16. All six time points were read simultaneously, blinded to time, using the Outcome Measures in Rheumatology Clinical Trials RA MRI scoring system. Primary outcome was change in synovitis score in the CZP group; secondary outcomes were change in bone oedema (osteitis) and erosion scores and clinical outcome measures.

Results Forty patients were treated (27 CZP, 13 placebo $\rightarrow$ CZP), and $36(24$ CZP, 12 placebo $\rightarrow$ CZP) completed week 16. In the CZP group, there were significant reductions from baseline synovitis (HodgesLehmann estimate of median change, $-1.5, p=0.049$ ) and osteitis scores $(-2.5, p=0.031)$ at week 16 . Numerical, but statistically insignificant, MRI inflammation reductions were observed at weeks $1-2$ in the CZP group. No significant change was seen in bone erosion score. Improvements across all clinical outcomes were seen in the CZP group.

Conclusions CZP reduced MRI synovitis and osteitis scores at week 16, despite small sample size and the technical challenge of reading six time points simultaneously. This study provides essential information on optimal MRI timing for subsequent trials.

Trial registration number ClinicalTrials.gov, NCT01235598.

\section{INTRODUCTION}

Rheumatoid arthritis (RA) is a chronic inflammatory disease, characterised by joint inflammation and damage. Early joint inflammation, including synovitis and bone oedema (osteitis), is an important predictor of subsequent structural damage, ${ }^{1-4}$ and reliable tools are needed for its measurement. MRI can detect early joint inflammation with high sensitivity and without the use of radiation ${ }^{5}$ and allows earlier identification of joint damage than would be possible using conventional radiographs. ${ }^{6}$ Furthermore, MRI findings in RA are known to be strong predictors of subsequent radiographic progression. $^{37-9}$

The Outcome Measures in Rheumatology Clinical Trials (OMERACT) RA MRI scoring system (RAMRIS) is a validated scoring system for the assessment of synovitis, bone oedema and bone erosion, ${ }^{10}$ that is, joint inflammation and damage in RA, and changes in synovitis and bone oedema at 12 weeks after initiation of anti-tumour necrosis factor (anti-TNF) therapy have been reported to be significant in several clinical trials. ${ }^{11}$ However, no study has yet looked for the earliest time point when an anti-TNF therapy effect on synovitis and other imaging signs of active joint inflammation can be documented. Certolizumab pegol (CZP), a PEGylated Fc-free anti-TNF, is an ideal agent to study the issue, as clinical response is observed as early as 1 week following initiation of CZP therapy. ${ }^{12}$

This is the first report of the MAgnetic Resonance image VErified earLy respOnse on rheUmatoid factor positive arthritiS (MARVELOUS) randomised placebo-controlled study (NCT01235598). The main aim of this study was, by performing MRIs before and after initiation of CZP treatment at weeks 1,2 , 4,8 and 16 , to identify the first time point of an MRI-verified response to CZP in patients with RA.

\section{METHODS}

\section{Patients}

The study population was $\geq 18$ years of age with adult-onset RA of between 3 months and 15 years duration, as defined by the 1987 American College of Rheumatology (ACR) classification criteria. ${ }^{13}$ Eligible patients had active, moderate-to-severe RA, with three or more tender joints and three or more swollen joints ( 28 joint count) at baseline, including one or more tender joint and one or more swollen joint in the joint area imaged (unilateral wrist and second to fifth metacarpophalangeal (MCP) joints). Inclusion criteria also required that patients had immunoglobulin $M$ rheumatoid factor and/or anti-citrullinated protein positivity, with serum creatinine within normal limits $(<4$ weeks prior to 
baseline), and stable disease-modifying antirheumatic drug therapy for at least 12 weeks prior to baseline.

Patients were excluded if they had received more than one previous biological agent, had ever received rituximab or tocilizumab or had treatment with infliximab or abatacept $<3$ months prior to baseline or adalimumab, golimumab or etanercept $<2$ months prior to baseline. Patients with a secondary, noninflammatory musculoskeletal condition or any other inflammatory arthritis were also excluded, as were those with a history of chronic infections or a serious infection $<6$ months prior to baseline and those with a primary failure to anti-TNF therapy.

\section{Study design}

This phase IIIb study (NCT01235598) was conducted between December 2010 and May 2013 and consisted of a 16-week, multicentre, randomised, double-blind phase, which was placebocontrolled for the first 2 weeks (figure 1), followed by a 24 -week open-label extension and a 2.5 -month safety follow-up. The study protocol was approved by the Institutional Review Board/ Independent Ethics Committee as defined in local regulations and performed according to the Declaration of Helsinki. Patients were recruited from Sweden, Denmark, the Netherlands and Poland, and all patients provided written consent.

Patients were randomised 2:1 via Interactive Voice Response System to either CZP every 2 weeks ( $400 \mathrm{mg}$ loading dose at weeks 0,2 and 4, and then $200 \mathrm{mg}$ every 2 weeks to week 16; CZP group) or placebo ( $0.9 \%$ saline) at day 0 followed by CZP every 2 weeks (400 mg loading dose at weeks 2, 4 and 6, and then $200 \mathrm{mg}$ every 2 weeks to week 16; placebo $\rightarrow$ CZP group; figure 1A). Contrast-enhanced MRI of unilateral wrist and second to fifth MCP joints (site selected based on the highest number of clinically swollen joints within the scanned joint area) was acquired at baseline (week 0) and weeks 1, 2, 4, 8 and 16.

\section{Study drug}

Placebo and CZP solutions were delivered by subcutaneous injection. Due to differences in the presentation and viscosity of CZP and placebo, all study treatments (CZP and placebo) were administered by unblinded study centre personnel to maintain study blinding. The personnel administering the injections had no involvement in the study other than performing the erythrocyte sedimentation rate analysis.

\section{MRI assessments}

MRIs were obtained at 10 different MRI facilities using either Philips, Siemens or General Electrics 1.5 Tesla or 3.0 Tesla whole-body configuration MRI machines. Reproducible positioning was ensured using a custom individualised splint for each hand of each patient in conjunction with the Syn-M-RA positioning device. Wrist and MCP joint regions were scanned separately. Biplanar slice alignment was used. MRI sequences included coronal and axial precontrast and postcontrast T1-weighted turbo spin echo MR images without fat suppression, and precontrast coronal short $\tau$ inversion recovery images, with a slice thickness of $2.5 \mathrm{~mm}$.

All MRIs were analysed by a rheumatologist (MØ) experienced in scoring according to the RAMRIS system. The reader was blinded to subject identity, study treatment and time point. All six time points (weeks $0,1,2,4,8$ and 16) were read simultaneously. Using the RAMRIS system, ${ }^{10}$ synovitis was scored $0-3$ in three wrist regions and in second to fifth MCP joints (total score range 0-21). Fifteen anatomical locations in each wrist and eight locations in each hand were assessed for osteitis (bone marrow oedema) and bone erosion. Osteitis was scored
0-3 and bone erosion 0-10 in each wrist and MCP joint bone (total score ranges 0-69 and 0-230, respectively). Cartilage loss or joint space narrowing (JSN) were not assessed by MRI as the statistical analysis plan was finalised before a JSN assessment method was added to the RAMRIS method. ${ }^{14} 15$

Intrareader reliability was assessed by randomly incorporating the full image sets (six scans) from four patients into the reads to be re-read a second time without the reader's knowledge, such that they were not aware when images for intrareader assessments were incorporated.

\section{Study endpoints}

The primary endpoint was change from baseline in OMERACT RAMRIS synovitis score in the CZP group. Secondary endpoints included the difference between change from baseline in OMERACT RAMRIS synovitis score for CZP versus placebo $\rightarrow \mathrm{CZP}$ at weeks 1 and 2, and clinical outcome measures including European League against Rheumatism (EULAR) response, ACR response criteria, Disease Activity Score 28 (DAS28) C reactive protein (CRP) score, Health Assessment Questionnaire-Disability Index (HAQ-DI) score and bone mineral density (BMD, as measured by digital X-ray radiogrammetry (DXR)). Additional secondary and exploratory endpoints included the change from baseline in MRI bone oedema (osteitis) and bone erosion scores, and the correlation of synovitis change from baseline at week 16 with EULAR response, ACR response, change from baseline in DAS28 (CRP) and change from baseline in hand BMD. Safety variables, including adverse events (AEs) and laboratory parameters, were also assessed.

\section{Statistical analysis}

Due to sparse information concerning MRI-based OMERACT RAMRIS synovitis scores, no formal sample size or power estimates were conducted.

All endpoint analyses were conducted in the full analysis set (FAS), which included all randomised patients who received at least one dose of study medication and who had a valid baseline efficacy assessment and at least one valid postbaseline efficacy assessment. Safety analyses were carried out using the safety set, which included all patients who received at least one dose of study medication.

The permutation test for matched pair data was used to analyse change from baseline within the CZP treatment group for synovitis, bone erosion and bone oedema scores at weeks 1 , 2, 4, 8 and 16. To determine the earliest time point at which a significant change occurred, fixed sequence testing was conducted beginning with the week 16 visit. If the test at week 16 was statistically significant, then the week 8 time point was analysed. Testing was continued in this manner until a nonsignificant result was obtained. Once a non-significant result was obtained, no further testing was allowed. The time point which corresponded to the last statistically significant result was declared the earliest time point at which OMERACT RAMRIS scores were significantly different from baseline. The change from baseline for synovitis, bone erosion and bone oedema scores are summarised using the exact Hodges-Lehmann estimate for median difference (for paired samples) and the corresponding 95\% CI.

The change from baseline for the synovitis scores at weeks 1 and 2 was compared between treatment groups (CZP vs placebo (placebo portion of the placebo $\rightarrow$ CZP treatment group)) using the Wilcoxon rank-sum test. The Hodges-Lehmann estimate for median difference (for independent samples) and 95\% CI were computed for weeks 1 and 2 . 
A

Double-Blind Phase

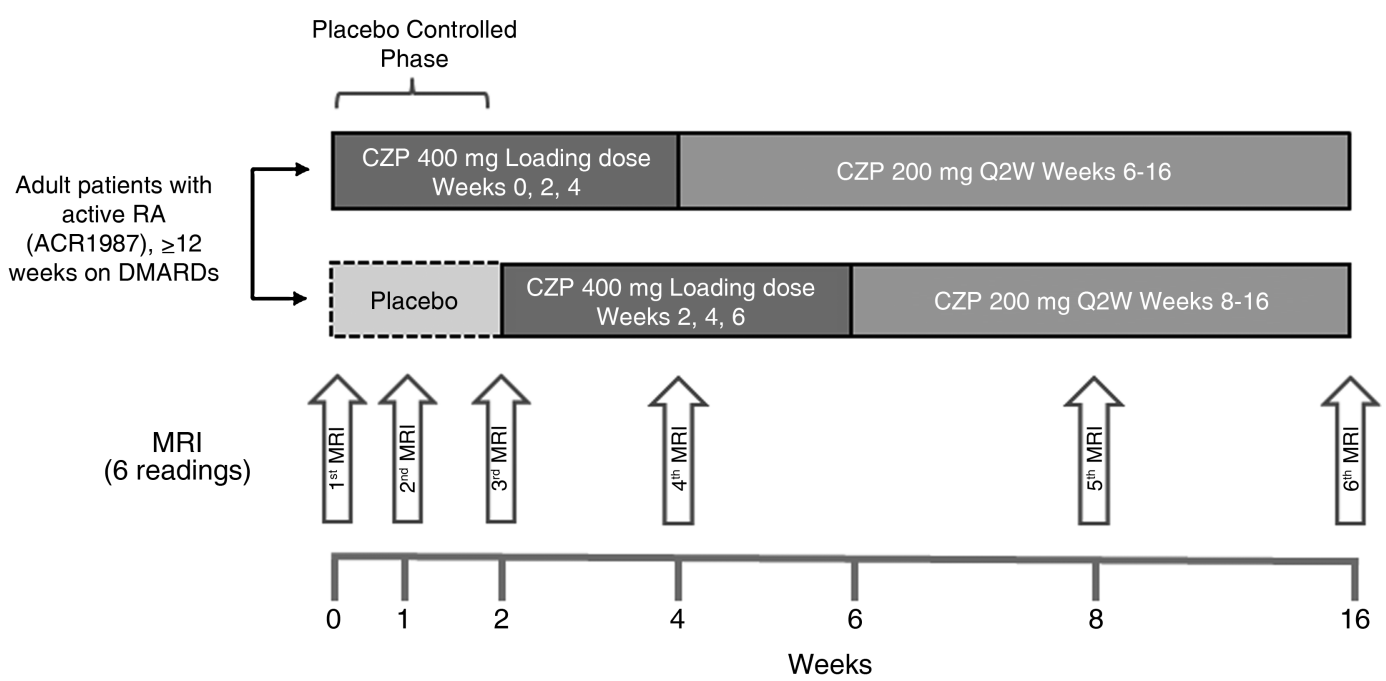

B

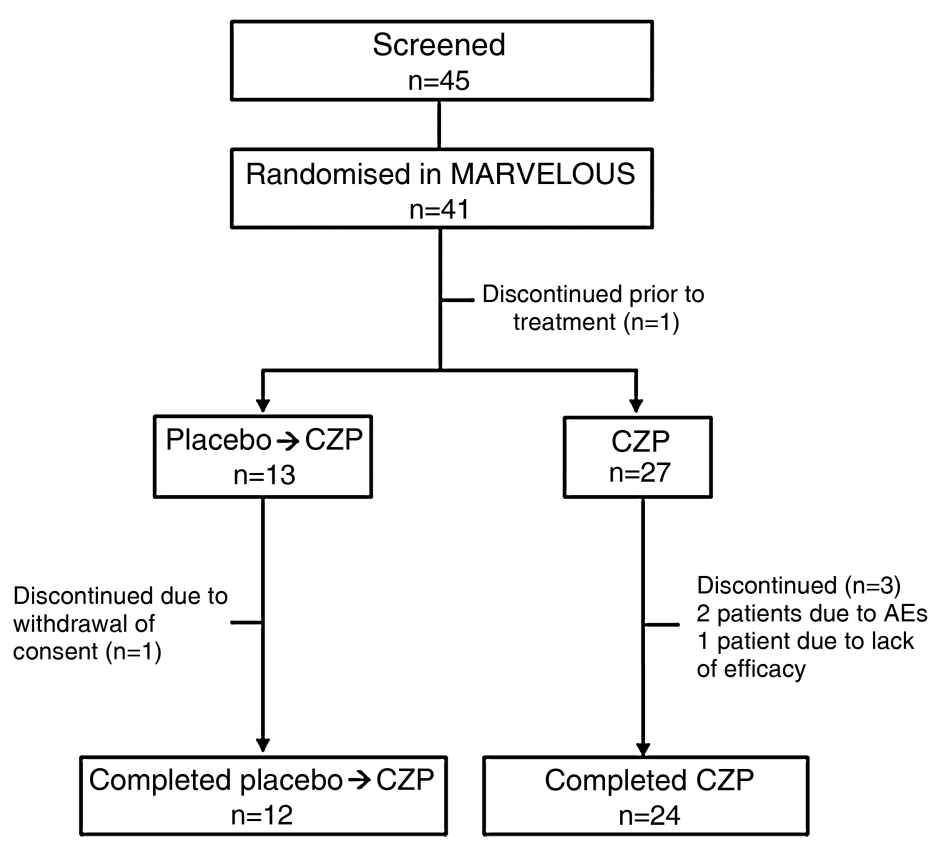

Figure 1 (A) Study design (double-blind period) and (B) patient disposition. ACR, American College of Rheumatology; AE, adverse event; CZP, certolizumab pegol; DMARDs, disease-modifying antirheumatic drug; MARVELOUS, MAgnetic Resonance image VErified earLy respOnse on rheUmatoid factor positive arthritis; RA, rheumatoid arthritis.

Spearman's rank correlation coefficient was used to assess the relationship between change from baseline to week 16 in synovitis score and the following clinical outcomes for the CZP group: EULAR response; ACR20, ACR50 and ACR70 responses; change from baseline in DAS28(CRP) score and change from baseline in BMD as measured by DXR.

Last observation carried forward imputation was used for synovitis analyses and observed data for all other outcomes. All significance testing was conducted using two-tailed tests and a statistical significance level of $\mathrm{p}<0.05$.

\section{RESULTS}

\section{Patient disposition and baseline characteristics}

Of 45 patients screened, 41 were randomised; 1 patient withdrew prior to treatment and was not included in the FAS. The FAS comprised 27 patients in the CZP group and 13 in the placebo $\rightarrow$ CZP group. During the double-blind phase, four patients discontinued treatment: one patient in the placebo $\rightarrow$ CZP group due to withdrawal of consent, and three patients in the CZP group, two due to AEs and one due to lack of efficacy (figure 1B). Patient baseline characteristics were similar across treatment groups, for both demographic and disease characteristics (table 1).

\section{RAMRIS parameters}

A significant reduction from baseline in synovitis score was reported in the CZP group at week 16 (Hodges-Lehmann estimate of median change, $-1.5, \mathrm{p}=0.049$; figure $2 \mathrm{~A}, \mathrm{C})$. The reduction from baseline was not significant at week 8 $(p=0.206)$, precluding further testing of earlier time points (figure 2A). The median decrease from baseline in synovitis 
Table 1 Patient characteristics at baseline: safety set

\begin{tabular}{|c|c|c|c|}
\hline & Placebo $\rightarrow$ CZP $(n=13)$ & CZP $(n=27)$ & All patients $(\mathrm{N}=40)$ \\
\hline \multicolumn{4}{|c|}{ Demographic characteristics: mean (SD), unless noted } \\
\hline Age, years & $48.3(14.4)$ & $51.3(12.6)$ & $50.4(13.1)$ \\
\hline Sex, \% female & 76.9 & 81.5 & 80.0 \\
\hline Weight, kg & $75.9(30.4)$ & $74.0(18.7)$ & $74.6(22.8)$ \\
\hline Time since diagnosis, years & $5.9(5.1)$ & $4.8(3.8)$ & $5.1(4.2)$ \\
\hline Concomitant MTX use, \% & 92.3 & 85.2 & 87.5 \\
\hline Prior anti-TNF therapy, \% & 15.4 & 22.2 & 20.0 \\
\hline \multicolumn{4}{|c|}{ Disease characteristics: mean (SD), unless noted } \\
\hline $\mathrm{CRP}, \mathrm{mg} / \mathrm{L}^{*}$ & $6.2(247.5)$ & $3.8(171.0)$ & $4.4(194.9)$ \\
\hline DAS28(CRP) & $5.3(1.2)$ & $5.1(1.1)$ & $5.1(1.1)$ \\
\hline IgM rheumatoid factor positivet (\%) & 92.3 & 92.6 & 92.5 \\
\hline Anti-CCP positive $\ddagger(\%)$ & 92.3 & 96.3 & 95.0 \\
\hline Tender joint count (28 joints) & $13.8(7.4)$ & $13.0(7.8)$ & $13.3(7.6)$ \\
\hline Swollen joint count (28 joints) & $9.9(6.3)$ & $10.0(6.4)$ & $10.0(6.3)$ \\
\hline HAQ-DI & $1.4(0.5)$ & $1.2(0.6)$ & $1.3(0.6)$ \\
\hline MRI synovitis score§ & $7.4(5.2)$ & $7.3(5.3)$ & $7.4(5.2)$ \\
\hline MRI osteitis scoreף & $7.1(7.3)$ & $7.2(9.9)$ & $7.2(9.0)$ \\
\hline MRI bone erosion Score** & $7.0(11.0)$ & $5.0(7.2)$ & $5.7(8.5)$ \\
\hline \multicolumn{4}{|c|}{$\begin{array}{l}\text { *Data show geometric mean (geometric coefficient of variation (\%)). } \\
\text { †Rheumatoid factor positive } \geq 14 \mathrm{IU} / \mathrm{mL} \text {. } \\
\text { ¥Anti-CCP positive } \geq 20 \text { ELISA units. } \\
\text { §On a scale from } 0 \text { to } 21 . \\
\text { IOn a scale of } 0-69 \text {. } \\
{ }^{* *} \text { On a scale of } 0-230 \text {. } \\
\text { CCP, cyclic citrullinated peptide; CRP, C reactive protein; CZP, certolizumab pegol; DAS, Disease Activity Score; HAQ-DI, Health Assessment Questionnaire-Disability Index; IgM, } \\
\text { immunoglobulin M; MTX, methotrexate; TNF, tumour necrosis factor. }\end{array}$} \\
\hline
\end{tabular}

score for CZP patients was numerically higher compared with placebo $\rightarrow$ CZP patients at weeks $1-16$, but the differences were not statistically significant.

The bone marrow oedema score was also significantly reduced from baseline at week 16 in the CZP group (HodgesLehmann estimate of median change, $-2.5, \mathrm{p}=0.031$ ), although not at earlier time points (figure $2 \mathrm{~B}, \mathrm{C}$ ). Similar to synovitis score, the median decrease in bone oedema scores was numerically higher in CZP patients compared with placebo $\rightarrow$ CZP patients at weeks $1-8$, although differences were not statistically significant. Bone erosion scores remained similar throughout the study, with no significant change from baseline score at week 16 in the CZP group (median change, -1.0).

Mean changes (SD) in synovitis score from baseline in the CZP group/placebo $\rightarrow$ CZP group respectively were $-0.6(1.8) /+0.1$ (1.0) at week $1,-0.4(1.6) /+0.2(1.4)$ at week $2,-0.4(1.6) /+0.2$ (1.2) at week $4,-0.7(2.6) /+0.2(1.5)$ at week 8 and $-1.0(2.3) /$ -0.2 (1.6) at week 16. Similarly, mean changes in the bone oedema score from baseline in the CZP group/placebo $\rightarrow$ CZP group were $-0.3(1.6) /+0.3(1.6)$ at week $1,-0.1(1.8) /+1.0(2.4)$ at week $2,-0.8(1.7) /+0.6(4.3)$ at week $4,-0.5(2.8) /-0.6(5.2)$ at week 8 and $-1.4(2.8) /-2.7(5.0)$ at week 16 .

For all RAMRIS parameters (synovitis, bone oedema, bone erosion), very good intrareader reliability (intraclass correlations $>0.90$ ) was observed, supporting the reliability of the data.

\section{Clinical outcomes}

Improvements were seen from week 1 in the CZP group across all clinical outcomes tested, including EULAR response, ACR20 response, median DAS28(CRP) score and median HAQ-DI score (figure 3). Placebo patients also showed rapid responses following treatment switch to CZP at week 2, and by week 16, placebo $\rightarrow$ CZP patients showed comparable ACR and EULAR responses to patients receiving CZP from week 0. At week 16, 95.2\% of CZP-treated patients achieved a moderate or good EULAR response (figure 3A), and 86.4\% achieved an ACR20 response, with a median DAS28(CRP) score of 2.48 (figure 3B, C, respectively).

Both treatment arms also showed improvements from baseline in median HAQ-DI score (placebo $\rightarrow$ CZP patients: 1.5 at baseline and 0.7 at week 16; CZP patients: 1.1 at baseline and 0.25 at week 16; figure $3 \mathrm{D}$ ).

The correlations between clinical efficacy parameters and changes from baseline in synovitis were calculated. At week 16, there were no statistically significant correlations between change from baseline in synovitis score and clinical outcomes for the CZP group ( $p>0.10$ for all parameters tested, including EULAR response (correlation coefficient, $-0.20 ; p=0.394$ ) and ACR20 response (correlation coefficient, $-0.11 ; \mathrm{p}=0.625)$ ).

\section{Digital X-ray radiogrammetry}

Very little change from baseline in BMD, as measured with DXR, was observed in either treatment group (in placebo $\rightarrow$ CZP patients mean BMD was $0.55 \mathrm{~g} / \mathrm{cm}^{2}$ at baseline and $0.54 \mathrm{~g} / \mathrm{cm}^{2}$ at week 16 and $0.56 \mathrm{~g} / \mathrm{cm}^{2}$ at both baseline and week 16 in CZP patients).

\section{Safety}

Most AEs were mild or moderate and the rates of AEs were similar between the placebo $\rightarrow \mathrm{CZP}$ and CZP arms during the first 2 weeks (table 2). The most frequent AEs were infections and infestations, of which the most commonly reported events were herpes viral infections and upper respiratory tract infections (both $n=5(12.5 \%)$ in overall CZP group). There were no serious infections or deaths and there was a low incidence of withdrawals due to AEs. 


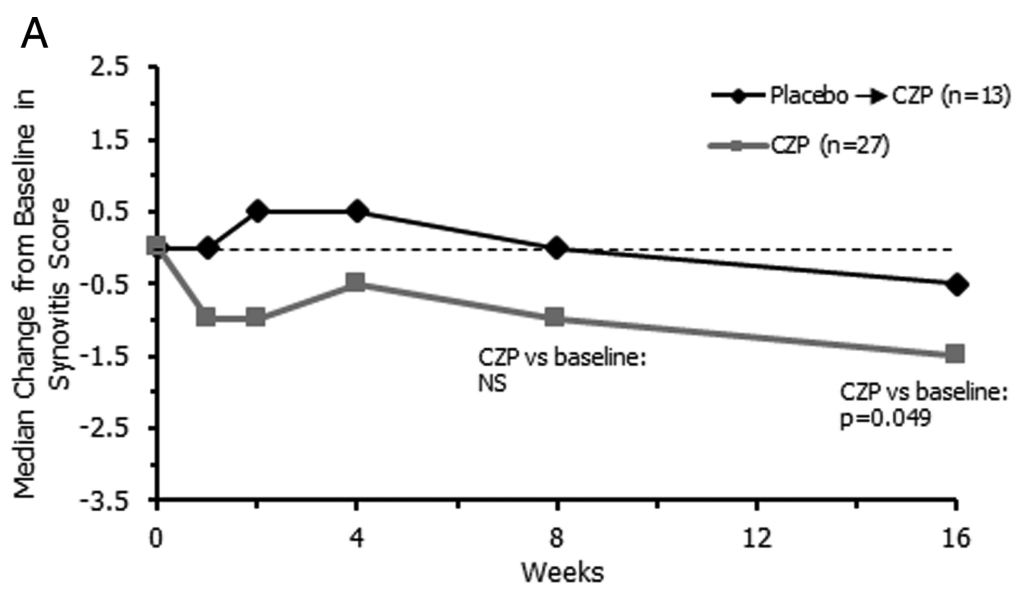

B

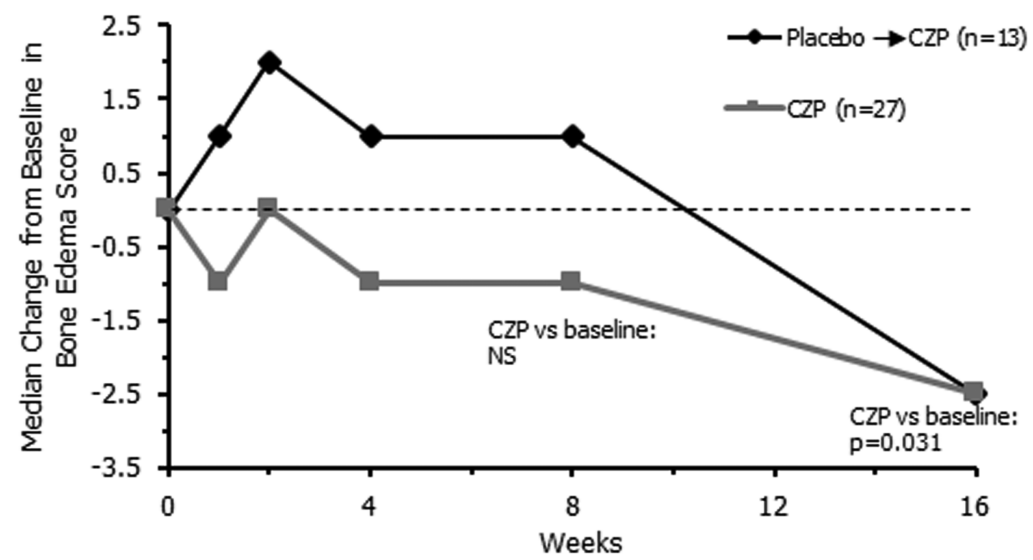

\begin{tabular}{|c|c|c|c|c|c|c|}
\hline & & Week 1 & Week 2 & Week 4 & Week 8 & Week 16 \\
\hline \multirow{2}{*}{$\begin{array}{l}\text { Change in } \\
\text { Synovitis } \\
\text { Score, } \\
\text { median } \\
(95 \% \text { CI) }\end{array}$} & Placebo $\rightarrow$ CZP & $\begin{array}{c}0.0 \\
(-1.0,2.0)\end{array}$ & $\begin{array}{c}0.5 \\
(-1.0,2.0)\end{array}$ & $\begin{array}{c}0.5 \\
(-1.0,1.5)\end{array}$ & $\begin{array}{c}0.0 \\
(-2.0,2.0)\end{array}$ & $\begin{array}{c}-0.5 \\
(-2.0,2.0)\end{array}$ \\
\hline & CZP & $\begin{array}{c}-1.0 \\
(-2.5,0.0)\end{array}$ & $\begin{array}{c}-1.0 \\
(-2.0,0.5)\end{array}$ & $\begin{array}{c}-0.5 \\
(-1.5,0.5)\end{array}$ & $\begin{array}{c}-1.0 \\
(-3.0,1.0) \text { NS }\end{array}$ & $\begin{array}{c}-1.5 \\
(-3.0,0.0) \\
p=0.049^{\circ}\end{array}$ \\
\hline \multirow{2}{*}{$\begin{array}{l}\text { Change in } \\
\text { Bone Edema } \\
\text { Score, } \\
\text { median } \\
(95 \% \mathrm{CI})\end{array}$} & Placebo $\rightarrow$ CZP & $\begin{array}{c}1.0 \\
(\mathrm{NC}, \mathrm{NC})^{\mathrm{C}}\end{array}$ & $\begin{array}{c}2.0 \\
(-1.0,7.0)\end{array}$ & $\begin{array}{c}1.0 \\
(-8.0,12.0)\end{array}$ & $\begin{array}{c}1.0 \\
(-7.0,3.5) \\
\end{array}$ & $\begin{array}{c}-2.5 \\
(-10.5,1.0)\end{array}$ \\
\hline & CZP & $\begin{array}{c}-1.0 \\
(-2.5,1.0)\end{array}$ & $\begin{array}{c}0.0 \\
(-1.5,1.0)\end{array}$ & $\begin{array}{c}-1.0 \\
(-2.5,0.0)\end{array}$ & $\begin{array}{c}-1.0 \\
(-3.0,1.0) \text { NS }\end{array}$ & $\begin{array}{c}-2.5 \\
(-5.0,0.0) \\
p=0.031^{\circ}\end{array}$ \\
\hline
\end{tabular}

sestimate from Hodges-Lehmann procedure

op values indicate statistically significant change from baseline (permutation test with general scores)

${ } \mathrm{NC}=$ not calculated due to small number of changes from baseline

$\mathrm{CI}$, confidence interval; CZP, certolizumab pegol, NS, non-significant

Figure 2 Changes in Outcome Measures in Rheumatology Clinical Trials (OMERACT) rheumatoid arthritis MRI scoring system (RAMRIS) parameters in the placebo $\rightarrow$ certolizumab pegol (CZP) group and CZP group. (A) Median change from baseline in synovitis score over 16 weeks. (B) Median change from baseline in bone oedema score over 16 weeks. (C) Table summarising median change in synovitis and bone oedema score for each MRI reading. $\mathrm{Cl}$, confidence interval; NS, non-significant.

\section{DISCUSSION}

The present paper, describing the MARVELOUS randomised placebo-controlled study, is to our knowledge, the first paper in which multiple repeated MRIs have been carried out following initiation of anti-TNF therapy. This allowed systematic investigation of the earliest time point when changes in signs of inflammation can be recognised by MRI. In a sample of only 27 patients with RA, statistically significant improvements in synovitis and osteitis were detected at week 16 , but not at week 8 .
Although differences from baseline were not statistically significant at week 8, a numerical decrease in median synovitis and osteitis scores was also observed at weeks 1-8 in patients receiving CZP from baseline.

At week 16, when high ACR and EULAR response rates were seen, indicating good clinical response to CZP, significant reductions from baseline occurred in two of the inflammatory OMERACT RAMRIS parameters: synovitis and bone oedema. These results are consistent with other studies assessing the effect of 
A

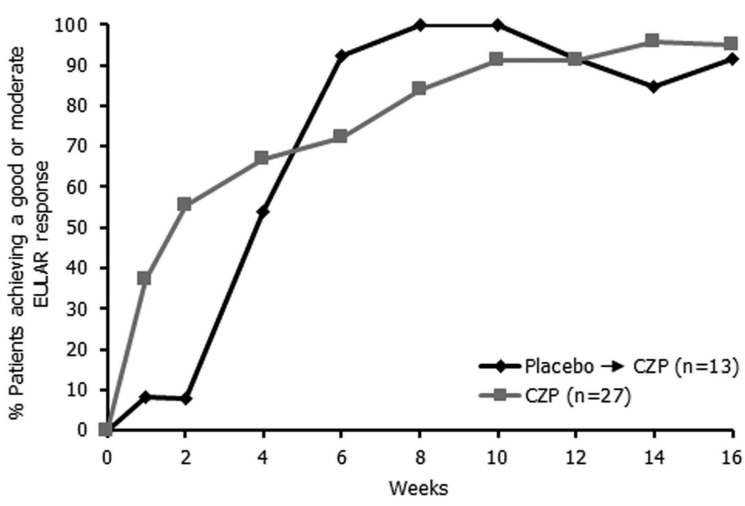

C

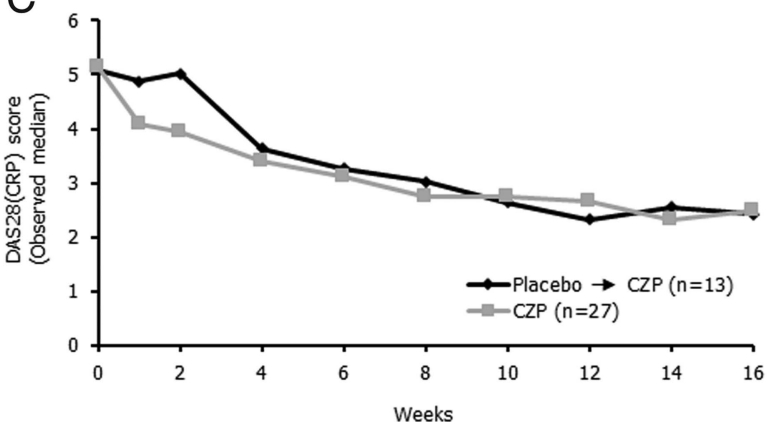

B
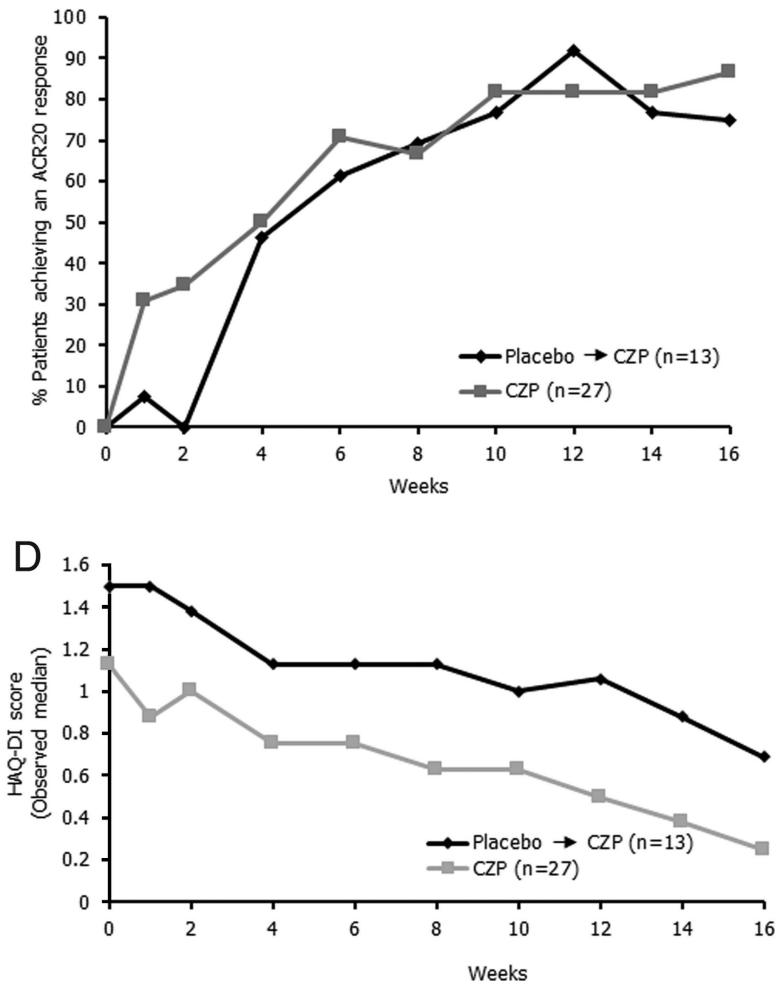

Figure 3 Clinical efficacy to week 16, as measured by (A) European League against Rheumatism (EULAR) response, (B) American College of Rheumatology (ACR) 20 response, (C) median Disease Activity Score 28 (DAS28) C reactive protein (CRP) score and (D) patient-reported outcomes measured by median Health Assessment Questionnaire-Disability Index (HAQ-DI) score (observed data). CZP, certolizumab pegol.

RA therapies on MRI outcomes where, despite small sample sizes, therapeutic efficacy can be discriminated in $<6$ months. ${ }^{11}$

The OMERACT RAMRIS synovitis score reflects the volume, or load of inflamed synovium; MRI synovitis has previously been shown to be a responsive measure of inflammation when evaluating anti-TNF therapy in the first year of treatment. ${ }^{16}$ The MARVELOUS study, therefore, shows that CZP reduces the load of inflammatory tissue, as assessed by a sensitive objective measure. This is in line with previous studies documenting the clinical efficacy of CZP. ${ }^{12} 17$ This study also provides important pathophysiological information, showing that changes in synovitis volume lag behind the clinical effect of anti-TNF therapy, which was already observed after 1-2 weeks. This could suggest that the immediate clinical effect of CZP is based on other factors than reduction of the synovitis mass, such as reduction in inflammatory cytokines or CRP.

Nevertheless, this early clinical effect is followed by robust pathoanatomical improvement in synovial inflammatory load and also in bone oedema, which has been demonstrated to reflect inflammatory infiltrates in the bone (osteitis) ${ }^{18} 19$ and to be closely related to subsequent erosive progression. ${ }^{2} 32021$ For instance, a prospective study of an early RA cohort showed that bone oedema

Table 2 Adverse events in the full safety set during 16 weeks of the MAgnetic Resonance image VErified earLy respOnse on rheUmatoid factor positive arthritiS (MARVELOUS) study

\begin{tabular}{|c|c|c|c|}
\hline Category & $\begin{array}{l}\text { Placebo week 0-2 } \\
\mathrm{n}=13, \mathrm{n}(\%)\end{array}$ & $\begin{array}{l}\text { CZP week 0-2 } \\
\mathrm{n}=27, \mathrm{n}(\%)\end{array}$ & $\begin{array}{l}\text { CZP at any time } \\
\mathrm{N}=40, \mathrm{n}(\%)\end{array}$ \\
\hline Any AEs & $5(38.5)$ & $7(25.9)$ & $26(65.0)$ \\
\hline \multicolumn{4}{|l|}{ AEs by severity } \\
\hline Mild & $3(23.1)$ & $7(25.9)$ & $17(42.5)$ \\
\hline Moderate & $2(15.4)$ & 0 & $8(20.0)$ \\
\hline Severe & 0 & 0 & $1(2.5)$ \\
\hline Discontinuations due to AEs & 0 & 0 & $2(5.0)$ \\
\hline Drug-related AEs & $1(7.7)$ & $4(14.8)$ & $13(32.5)$ \\
\hline Serious AEs & 0 & 0 & $2(5.0)$ \\
\hline Infections and infestations & $2(15.4)$ & $1(3.7)$ & $14(35.0)$ \\
\hline Deaths & 0 & 0 & 0 \\
\hline
\end{tabular}

Serious AEs were one case of coronary artery disease and one of sensory loss.

${ }^{*}$ Only AEs occurring while receiving CZP in either treatment arm are included. Results shown for the full safety set.

$A E$, adverse event; $C Z P$, certolizumab pegol. 
scored on MRI scans of the wrist and MCP joints was the strongest predictor of radiographic progression in the subsequent 2 years. ${ }^{3}$ Furthermore, in a recent randomised controlled trial, an early reduction in bone marrow oedema was shown to predict radiographic damage up to 2 years after treatment initiation. ${ }^{8}$ The MARVELOUS study, therefore, supports CZP reduction of erosive progression, although the definite conclusion that CZP inhibits radiographic progression requires documentation by radiographic follow-up. This was not done in the present study, but has been previously documented in clinical trials of 10 times as many patients. ${ }^{12} 17$ In addition, there was no decrease in BMD in either the placebo $\rightarrow$ CZP or CZP groups during the MARVELOUS study, supporting CZP suppression of rheumatoid inflammation.

Most previous studies investigating the efficacy of biological drugs on MRI outcomes in RA have performed MRIs at 12-26 weeks, demonstrating significant reductions in synovitis and osteitis. ${ }^{11}$ A recent study of the anti-interleukin 6 monoclonal antibody tocilizumab demonstrated consistent reductions of synovitis at week 12 , but not at week 2 , where a reduction was only seen in one of the groups. ${ }^{22}$ In the present study, MRI was not performed at week 12. A Spanish investigator-initiated study of the anti-TNF inhibitor etanercept showed a significant reduction of synovitis, but not of bone oedema, after 6 weeks of etanercept therapy. ${ }^{23}$ The MARVELOUS study did not reveal a statistical improvement so early, which may be related to the lower initial synovitis and bone oedema scores, or due to the fact that the MARVELOUS study simultaneously evaluated six time points, whereas only two time points were evaluated in the Spanish study. ${ }^{23}$

Reading of MRI data was carried out across all six time points simultaneously, by a reader blinded both to time and treatment arm. The interpretation of these images was challenging, due to the temporal proximity of the time points used (eg, weeks 0,1 and 2) and the resultant small changes occurring between them. The use of fewer time points (and therefore potentially greater distinctions between them) might have improved sensitivity, which possibly could have led to greater discrimination among images at earlier time points.

Inter-reader reliability was not assessed in the present study, as a high agreement between $\mathrm{M} \varnothing$ and other internationally well-known readers has previously been documented. ${ }^{5} 24$ Instead, intrareader reliability was assessed and was found to be very high. We find it unlikely that assessment of a subset of the patients by another reader would significantly change the results. However, using only a single reader's scores, rather than averaged scores from two independent readers, could have limited the statistical power for detecting small changes.

It is also possible that more advanced MRI techniques, such as dynamic contrast-enhanced MRI, which has previously been shown to be very sensitive to change and closely related to histological signs of inflammation in RA joints, ${ }^{25} 26$ would improve the ability to show early change. The issue that only relatively few joints could be examined by MRI, which potentially limits the sensitivity to change of the MRI technique, may in the future be overcome by applying whole-body MRI, which after further technical improvement could provide an 'MRI joint count'. ${ }^{27}$

This study included a small group of 13 patients treated with placebo for a short period ( 2 weeks), who had MRI repeated twice (at weeks 1 and 2) during the placebo period. The fact that synovitis and osteitis scores did not decrease during placebo treatment has for the first time documented that MRI outcomes are not compromised by any placebo effect, that is, the expectation of the patient to receive effective therapy does not improve synovitis or bone oedema on MRI. This supports the use of MRI as objective measure of RA disease activity.
In conclusion, this first study with multiple MRIs following initiation of anti-TNF therapy showed reduced OMERACT RAMRIS synovitis and bone oedema scores at week 16 . This confirms, in agreement with previous MRI studies of anti-TNF therapies, the effect of CZP on objective measures of synovitis volume and extent of osteitis, that is, on reducing inflammation in synovium and bone. This was observed despite the small sample size and the technical challenges of reading six time points simultaneously. Numerical, but statistically insignificant, reductions of MRI inflammation were also observed at weeks $1-8$ in patients receiving CZP from baseline. This study provides important information on optimal MRI timing for subsequent trials.

\author{
Author affiliations \\ ${ }^{1}$ Copenhagen Center for Arthritis Research, Copenhagen University Hospital at \\ Glostrup, Glostrup, Denmark \\ ${ }^{2}$ Department of Rheumatology \& Inflammation Research, Institute of Medicine, \\ The Sahlgrenska Academy, University of Gothenburg, Gothenburg, Sweden \\ ${ }^{3}$ Department of Rheumatology, Gentofte Hospital, Gentofte, Denmark \\ ${ }^{4}$ University Medical Center Utrecht, Utrecht, The Netherlands \\ ${ }^{5}$ Medica Pro Familia, Warsaw, Poland \\ ${ }^{6}$ Rheuma Medicus, Warsaw, Poland \\ ${ }^{7}$ UCB Pharma, Brussels, Belgium \\ ${ }^{8}$ UCB Pharma, Raleigh, North Carolina, USA \\ ${ }^{9}$ UCB Pharma, Stockholm, Sweden \\ ${ }^{10}$ Department of Rheumatology, The Parker Institute, Frederiksberg, Denmark
}

Acknowledgements The authors acknowledge Matladi N. Ndlovu PhD, UCB Pharma, Brussels, Belgium, for publication coordination and Costello Medical Consulting, UK, for writing and editorial assistance, which was funded by UCB Pharma.

Contributors All authors were involved in planning for the analysis of data, reviewed the primary data, reviewed and approved each draft of the manuscript including approval of the final version.

\section{Funding UCB Pharma.}

Competing interests $M \varnothing$ has received grant/research support from Abbott, Pfizer and Centocor, has acted as a consultant for Abbott, Pfizer, Merck, Roche, and UCB Pharma and has taken part in speakers bureaus for Abbott, Pfizer, Merck, BMS, UCB Pharma, and Mundipharma; LTHJ has received grant/research support from Pfizer and has acted as a paid instructor for Abbvie, BMS, MSD, Pfizer and UCB Pharma; MSH has acted as sponsored investigator for UCB Pharma and participated as an advisory board member for Roche; JWJB has received grant/research support from Roche, UCB, Pfizer, MSD and BMS and has received consultancy fees from Roche, UCB, Pfizer, MSD, BMS and Jansen; FS, RH and BS-E are employees of UCB Pharma; HB has received consulting fees, honoraria, research or institutional support, educational grants, equipment, services or expenses from Abbott, Amgen, AstraZeneca, Aventis, Bristol Myers Squibb, Cambridge Nutritional Foods, Dansk Droge, Eurovita, Ferrosan, GlaxoSmithKline, Hoechst, LEO, Lundbeck, MSD, Mundipharma, Norpharma, NutriCare, Nycomed, Pfizer, Pharmacia, Pierre-Fabre, Proctor\&Gamble, Rhone-Poulenc, Roche, Roussel, Schering-Plough, Searle, Serono, UCB Pharma and Wyeth.

\section{Patient consent Obtained.}

Ethics approval The study protocol was approved by an Ethics Committee at each of the participating sites.

Provenance and peer review Not commissioned; externally peer reviewed.

Open Access This is an Open Access article distributed in accordance with the Creative Commons Attribution Non Commercial (CC BY-NC 4.0) license, which permits others to distribute, remix, adapt, build upon this work non-commercially, and license their derivative works on different terms, provided the original work is properly cited and the use is non-commercial. See: http://creativecommons.org/ licenses/by-nc/4.0/

\section{REFERENCES}

1 Aletaha D, Smolen J, Ward MM. Measuring function in rheumatoid arthritis: Identifying reversible and irreversible components. Arthritis Rheum 2006;54:2784-92.

2 Boyesen $\mathrm{P}$, Haavardsholm EA, Østergaard M, et al. MRI in early rheumatoid arthritis: synovitis and bone marrow oedema are independent predictors of subsequent radiographic progression. Ann Rheum Dis 2011;70:428-33.

3 Hetland ML, Ejbjerg B, Horslev-Petersen $\mathrm{K}$, et al. MRI bone oedema is the strongest predictor of subsequent radiographic progression in early rheumatoid arthritis. Results from a 2-year randomised controlled trial (CIMESTRA). Ann Rheum Dis 2009;68:384-90. 
4 Van Leeuwen M, Van der Heijde D, Van Rijswijk M, et al. Interrelationship of outcome measures and process variables in early rheumatoid arthritis. A comparison of radiologic damage, physical disability, joint counts, and acute phase reactants. J Rheumatol 1994:21:425-9.

5 Haavardsholm EA, Østergaard M, Ejbjerg BJ, et al. Reliability and sensitivity to change of the OMERACT rheumatoid arthritis magnetic resonance imaging score in a multireader, longitudinal setting. Arthritis Rheum 2005;52:3860-7.

6 Østergaard M, Hansen M, Stoltenberg M, et al. New radiographic bone erosions in the wrists of patients with rheumatoid arthritis are detectable with magnetic resonance imaging a median of two years earlier. Arthritis Rheum 2003;48:2128-31.

7 Haavardsholm EA, Bøyesen $P$, Østergaard M, et al. Magnetic resonance imaging findings in 84 patients with early rheumatoid arthritis: bone marrow oedema predicts erosive progression. Ann Rheum Dis 2008;67:794-800.

8 Baker JF, Østergaard M, Emery $\mathrm{P}$, et al. Early MRI measures independently predict 1-year and 2-year radiographic progression in rheumatoid arthritis: secondary analysis from a large clinical trial. Ann Rheum Dis 2014;73:1968-74.

9 Gandjbakhch F, Haavardsholm EA, Conaghan PG, et al. Determining a magnetic resonance imaging inflammatory activity acceptable state without subsequent radiographic progression in rheumatoid arthritis: results from a followup MRI study of 254 patients in clinical remission or low disease activity. J Rheumatol 2014;41:398-406.

10 Østergaard M, Peterfy C, Conaghan P, et al. OMERACT Rheumatoid Arthritis Magnetic Resonance Imaging Studies. Core set of MRI acquisitions, joint pathology definitions, and the OMERACT RA-MRI scoring system. J Rheumato/ 2003;30:1385-6.

11 Peterfy C, Østergaard M, Conaghan PG. MRI comes of age in RA clinical trials. Ann Rheum Dis 2013:72:794-6.

12 Keystone $E$, Heijde DVD, Mason D, et al. Certolizumab pegol plus methotrexate is significantly more effective than placebo plus methotrexate in active rheumatoid arthritis: findings of a fifty-two-week, phase III, multicenter, randomized, double-blind placebo-controlled, parallel-group study. Arthritis Rheum 2008;58:3319-29.

13 Arnett FC, Edworthy SM, Bloch DA, et al. The American Rheumatism Association 1987 revised criteria for the classification of rheumatoid arthritis. Arthritis Rheum 1988:31:315-24.

14 Østergaard M, Bøyesen P, Eshed I, et al. Development and preliminary validation of a magnetic resonance imaging joint space narrowing score for use in rheumatoid arthritis: potential adjunct to the OMERACT RA MRI scoring system. J Rheumatol 2011:38:2045-50

15 Døhn UM, Conaghan PG, Eshed I, et al. The OMERACT-RAMRIS Rheumatoid arthritis magnetic resonance imaging joint space narrowing score: Intrareader and interreader reliability and agreement with computed tomography and conventional radiography. J Rheumatol 2014;41:392-7.
16 Haavardsholm EA, Østergaard M, Hammer HB, et al. Monitoring anti-TNF $\alpha$ treatment in rheumatoid arthritis: responsiveness of magnetic resonance imaging and ultrasonography of the dominant wrist joint compared with conventional measures of disease activity and structural damage. Ann Rheum Dis 2009:68:1572-9.

17 Smolen J, Landewé RB, Mease $\mathrm{P}$, et al. Efficacy and safety of certolizumab pegol plus methotrexate in active rheumatoid arthritis: the RAPID 2 study. A randomised controlled trial. Ann Rheum Dis 2009;68:797-804.

18 Jimenez-Boj E, Nöbauer-Huhmann I, Hanslik-Schnabel B, et al. Bone erosions and bone marrow edema as defined by magnetic resonance imaging reflect true bone marrow inflammation in rheumatoid arthritis. Arthritis Rheum 2007;56:1118-24.

19 McQueen FM, Gao A, Østergaard M, et al. High-grade MRI bone oedema is common within the surgical field in rheumatoid arthritis patients undergoing joint replacement and is associated with osteitis in subchondral bone. Ann Rheum Dis 2007;66:1581-7

20 Hetland ML, Stengaard-Pedersen $\mathrm{K}$, Junker $\mathrm{P}$, et al. Radiographic progression and remission rates in early rheumatoid arthritis-MRI bone oedema and anti-CCP predicted radiographic progression in the 5-year extension of the double-blind randomised CIMESTRA trial. Ann Rheum Dis 2010;69:1789-95.

21 McQueen FM, Benton N, Perry D, et al. Bone edema scored on magnetic resonance imaging scans of the dominant carpus at presentation predicts radiographic joint damage of the hands and feet six years later in patients with rheumatoid arthritis. Arthritis Rheum 2003:48:1814-27.

22 Conaghan PG, Peterfy C, Olech E, et al. The effects of tocilizumab on osteitis, synovitis and erosion progression in rheumatoid arthritis: results from the ACT-RAY MRI substudy. Ann Rheum Dis 2014;73:810-16.

23 Lisbona MP, Maymo J, Perich J, et al. Etanercept reduces synovitis as measured by magnetic resonance imaging in patients with active rheumatoid arthritis after only 6 weeks. J Rheumatol 2008:35:394-7.

24 Conaghan PG, Emery P, Østergaard M, et al. Assessment by MRI of inflammation and damage in rheumatoid arthritis patients with methotrexate inadequate response receiving golimumab: results of the GO-FORWARD trial. Ann Rheum Dis 2011;70:1968-74.

25 Axelsen MB, Stoltenberg M, Poggenborg $R$, et al. Dynamic gadolinium-enhanced magnetic resonance imaging allows accurate assessment of the synovial inflammatory activity in rheumatoid arthritis knee joints: a comparison with synovial histology. Scand J Rheumatol 2012;41:89-94.

26 Axelsen MB, Poggenborg RP, Stoltenberg M, et al. Reliability and responsiveness of dynamic contrast-enhanced magnetic resonance imaging in rheumatoid arthritis Scand J Rheumatol 2013;42:115-22.

27 Axelsen MB, Eshed I, Duer-Jensen A, et al. Whole-body MRI assessment of disease activity and structural damage in rheumatoid arthritis: first step towards an MRI joint count. Rheumatology 2014;53:845-3. 